\title{
Teste de um método de processamento e integração de dados geofísicos: Identificação de anomalias e delimitação de potenciais áreas exploratórias de metais e minerais densos ao Sudeste da Austrália do Sul - AUS.
}

Autor: Luis Felipe de Melo Tassinari - Universidade Cruzeiro do Sul Miguel G Carminatti - Universidade Federal do Pampa (UNIPAMPA)

Copyright 2016, SBGf - Sociedade Brasileira de Geofísica

Este texto foi preparado para a apresentação no VII Simpósio Brasileiro de Geofísica, Ouro Preto, 25 a 27 de outubro de 2016. Seu conteúdo foi revisado pelo Comitê Técnico do VII SimBGf, mas não necessariamente representa a opinião da SBGf ou de seus associados. É proibida a reprodução total ou parcial deste material para propósitos comerciais sem prévia autorização da SBGt.

\section{Abstract}

This present research has as main procedure the mutual integration of different geophysical data with topographical Aster data. The geophysics methods used are airborne Magnetometry and Gamma ray spectrometry, a vast Gravimetric grid and aster topographic data. The main objective is to proof the efficacy and accuracy, or not, of this procedure for geological mapping and verify distinct ore responses in the area. At the end was confirmed the success of the applied methodology, given the fact the produced maps could show potential areas for different kinds of ore.

\section{Introdução}

Este trabalho consiste em uma série de processamento de dados gamaespectrométricos, magnetométricos e gravimétricos em escala regional, em uma área de mais de vinte mil quilômetros quadrados. Para sua realização foram empregados dados de transformações do campo magnético e gravimétrico e composições de imagens de contagem gama, propondo-se, assim, uma integração destes métodos de uma forma inovadora para a localização de alvos e zonas potenciais para ocorrência mineral, visando um posterior estudo mais detalhado da área.

A interpretação de dados de campos potenciais (gravimétricos e magnetométricos) é vastamente utilizada no delineamento do arcabouço estrutural de bacias e, sobretudo, na exploração mineral. Os processamentos de tais dados permitem não somente o traçado do arcabouço estrutural destas bacias, mas também possibilita a estimativa de profundidade das fontes associadas a estas feições. Tais técnicas constituem ferramentas importantes na construção de modelos geológico-geofísicos.

A interpretação de dados gamaespectrometricos fornece informações essenciais sobre a quantidade dos radioisótopos Potássio, Urânio e Tório. Ainda que este método seja limitado e extremamente raso (até $90 \mathrm{~cm}$ ), os elementos estudados são existentes em todos os solos; solos estes, que são produtos da pedogênese das rochas da área.

\section{Objetivos gerais}

O principal objetivo deste trabalho é utilizar técnicas de processamento de dados magnéticos e gamaespectrométricos aéreos e gravimétricos terrestres. Integrando estes com a geologia conhecida da região,

Definindo, assim, alvos com a probabilidade de ocorrência mineral na região cedida para estudo pela empresa Havilah Resources na Austrália do Sul. A comprovação da eficácia da metodologia aplicada foi verificada pela comparação das localidades destacadas pelo processamento e as localidades aonde depósitos já foram comprovados por meio de furos de sondagem.

\section{Objetivos específicos}

- Efetuar transformações do campo geomagnético e gerar imagens das mesmas para limitações de feições e estruturas geológicas correlacionáveis com a resposta magnética.

- Gerar mapas de dados gamaespectrométricos $(\mathrm{K}, \mathrm{U}$ e Th) e suas composições integrados com a topografia, com o intuito de delimitar formações superficiais e localidade de maior concentração de radioisótopos.

- Integrar e analisar imagens dos três métodos com a geologia e topografia para a localização de alvos, diminuindo, assim, as inconsistências intrínsecas a cada método.

- Comparar alvos localizados com a existência de depósitos já confirmados, validando ou não a metodologia aplicada

\section{Área de estudo e arcabouço geológico}

A área estudada abrange o Sudeste da Austrália do Sul (Figura 1), sendo esta região contida dentro da "Província de Curnamona", dentro das coordenadas ao leste 311732 $\mathrm{m}$ e $502172 \mathrm{~m}$, ao sul $6573608 \mathrm{~m}$ e $6461115 \mathrm{~m}$. O local foi escolhido pela abundância de dados disponíveis gratuitamente pelo governo da Austrália do Sul e apoio disponibilizado pelo CEO da companhia Havilah Resources, possuidora dos direitos de prospecção e mineração da região.

A região foco deste trabalho é extensa: mais de 20000 quilômetros quadrados e localiza-se em uma província predominantemente desértica. Sendo a província de Curnamona composta predominantemente por Rochas sedimentares deformadas, rochas vulcânicas e consecutivas intrusões graníticas com idades do paleoproterozóico ao mesoproterozóico. Estas rochas estão encobertas por camadas de sedimentos jovens do neoproterozóico, cambriano e até mais novas. (Figura 2) 


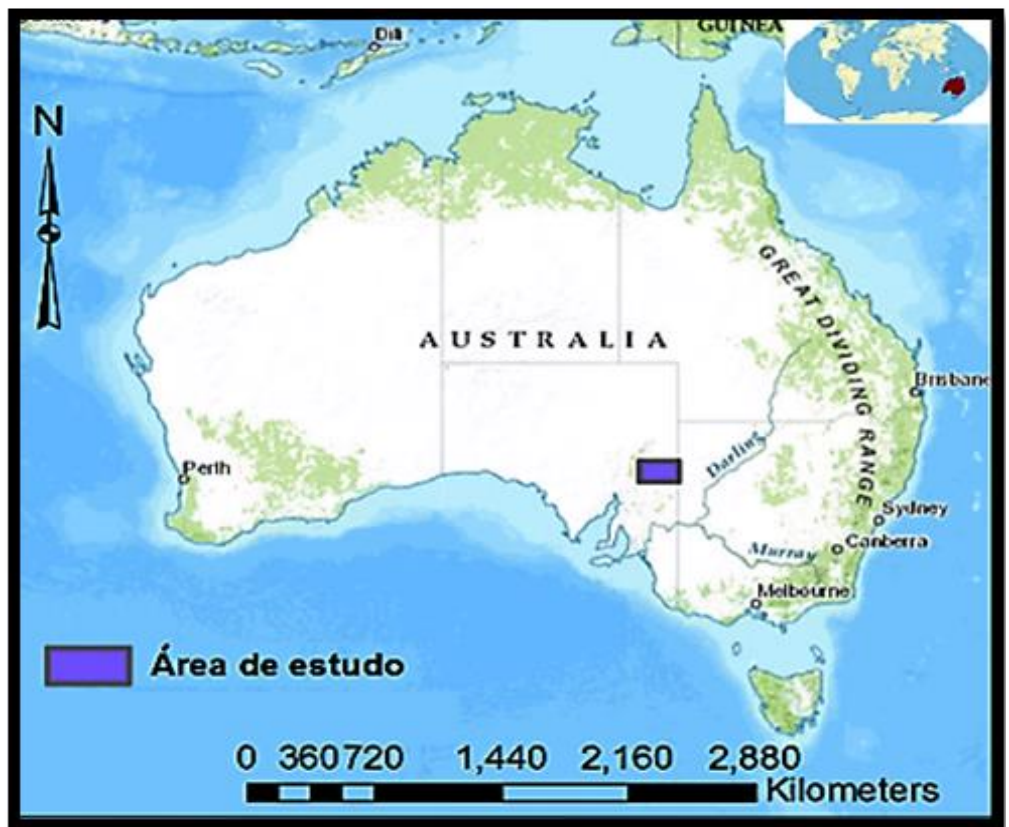

Figura 1: Localização da Área de estudo (DMC 2013

\section{Adaptado)}

Por possuir uma gelogia complexa apenas algumas serão destacadas. O contexto geológico da área $\mathrm{Cz}$ é predominantemente rochas sedimentares $\mathrm{e}$ sedimentos do cenozoico, com arenitos; siltitos; conglomerados; dolomitos e calcários. A formação $E$ do Cambriano composta por Calcários, siltitos, xistos; arenitos de grão fino e grauvaca. (Raymond, O. L. et al 2010).

Os grupos e formações com a sigla $L$ são datadas do Paleoproterozóico e no caso da formação $\mathrm{Lg}$ é constituída por intrusivas félsicas e gnaisses. O grupo Curnamona composto por rochas metassedimentares caracterizadas por cálcio-silicato minerais e feldspatos alcalinos, hematitas, magnetitas e baritas. O subgrupo Saltbush composto por Pelitos, xistos, rochas com alto grau de metamorfismo, gnaisse, granulitos e migmatitos com alto teor de hematitas. Além do grupo Strathearn composto por pelitos e arenitos finos. As formações com inicial $M$ têm sua origem no mesoproterozóico e são compostas por granitoides com alto teor de biotita. (Raymond, O. L. et al 2010)

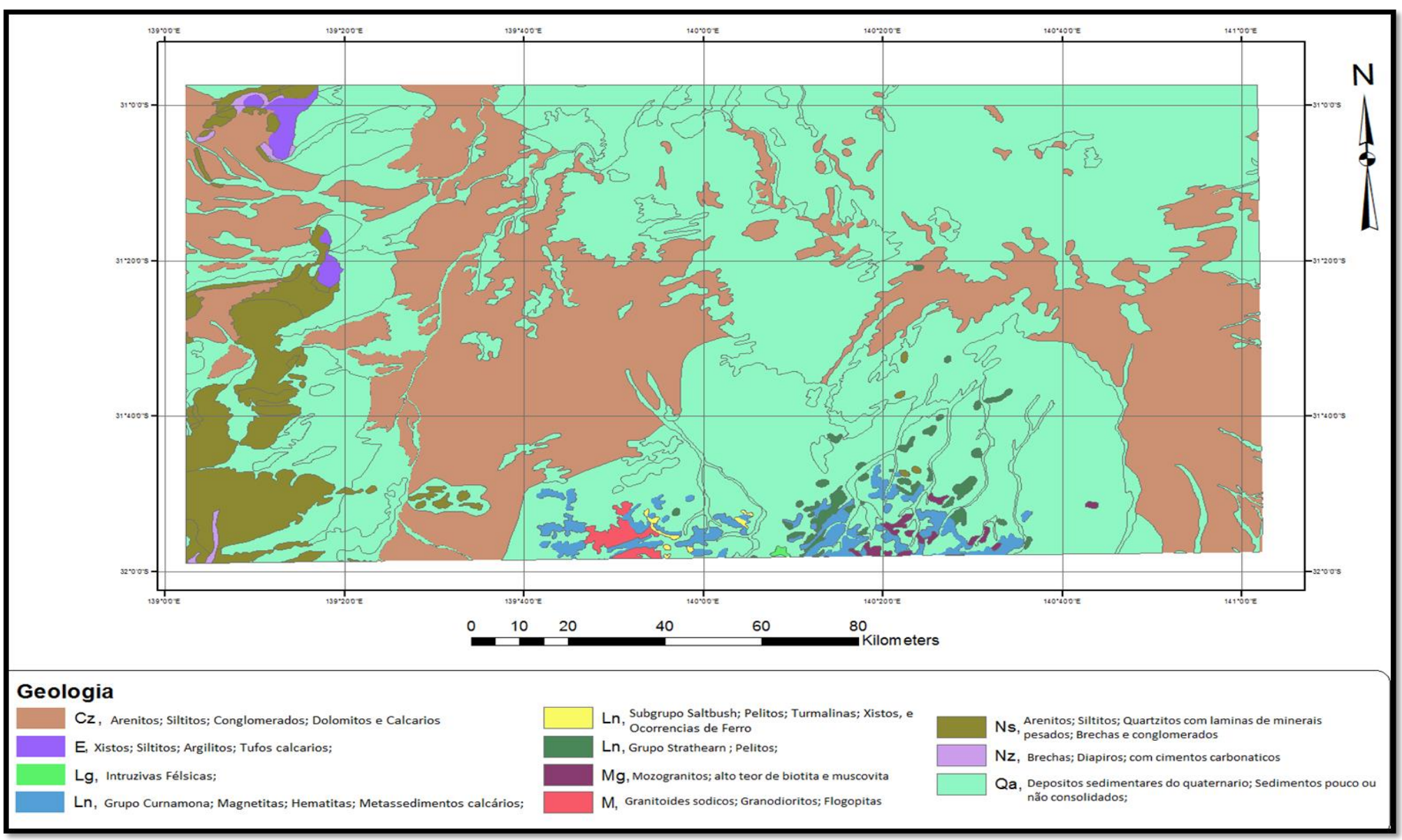

Figura 2: Geologia da Região em estudo (simplificado de Raymond, O. L. et al 2010) 


\section{Processamento de dados}

Inicialmente foram processados os dados magnetométricos da região estudada como pode ser observado na Figura 3.

O processamento de dados neste trabalho consiste na aplicação de transformações do campo sendo cada imagem/ produto gerada possuinte de suas particularidades para 0 destaque/realce de estruturas geológicas e obtenção de novas informações que estão intrínsecas a cada ferramenta matemática utilizada

Em seguida foram processados os dados de gravimetria apenas a FFT continuação para cima para obter noção do regional Bouguer da área foi efetuada. Posteriormente obtendo-se o residual gravimétrico da área (figura 4)

Linhas de voo foram interpoladas em $\mathrm{K}$, $\mathrm{U}$ e Th para a geração da imagem composta CMY. Distribuição dos radioelementos $\mathrm{K}, \mathrm{U}$ e Th.

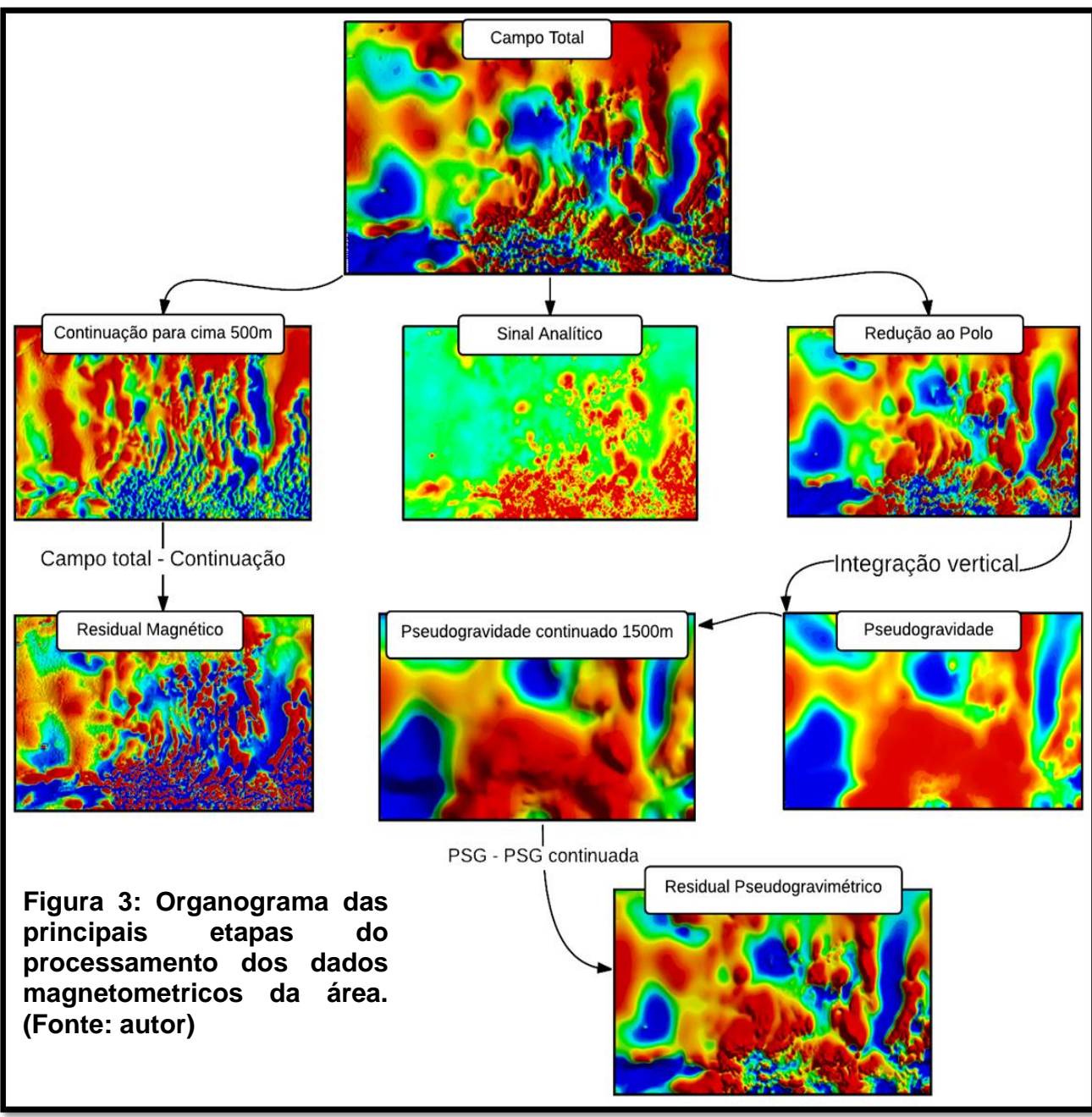

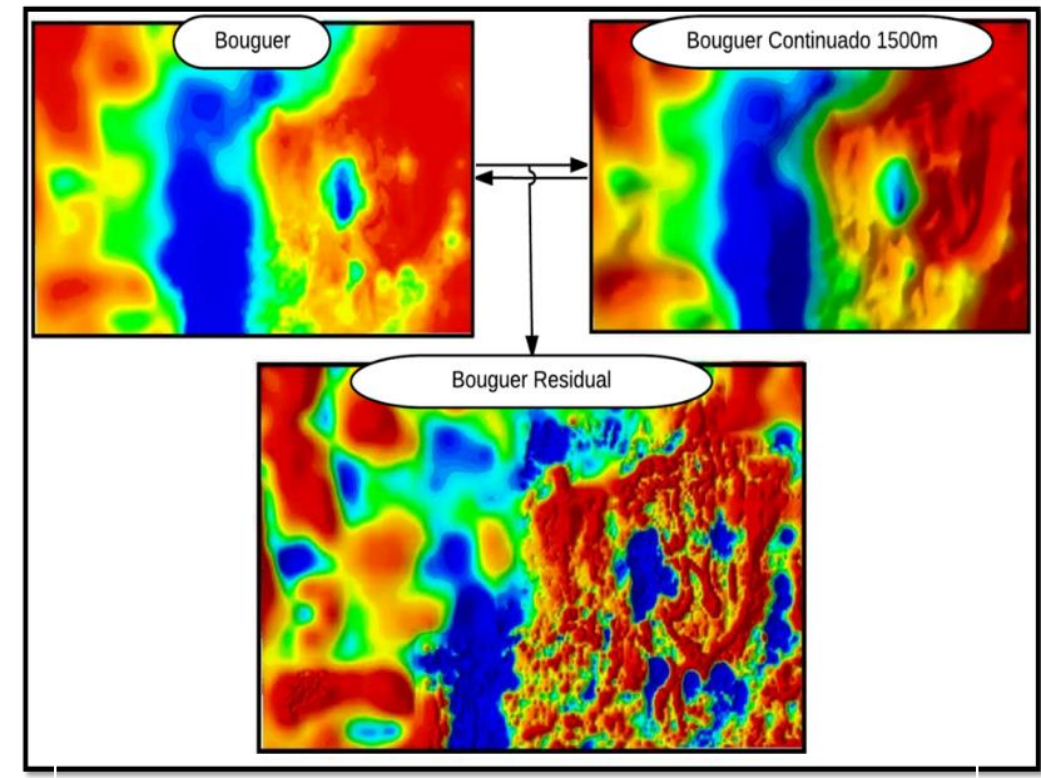

Figura 4: Fluxo de processamento de dados gravimétricos

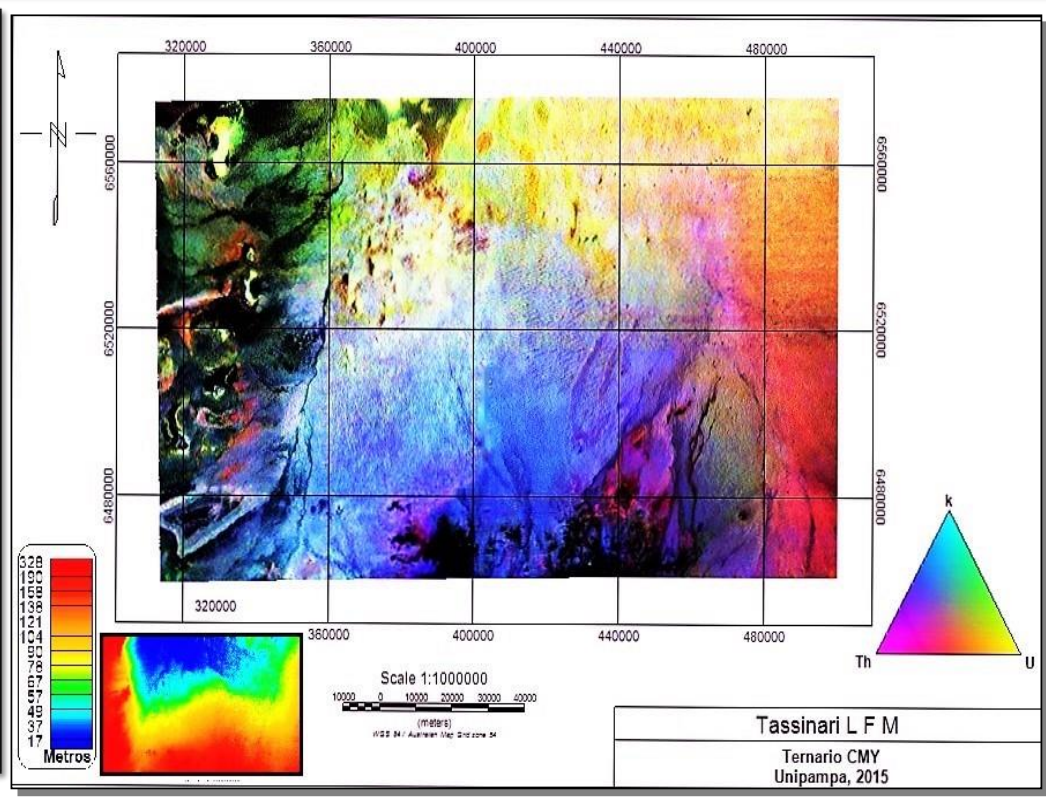

Figura 5: Mapa ternário da área com o mapa topográfico abaixo. Escuro = Maior concentração. Claro = menor concentração. 


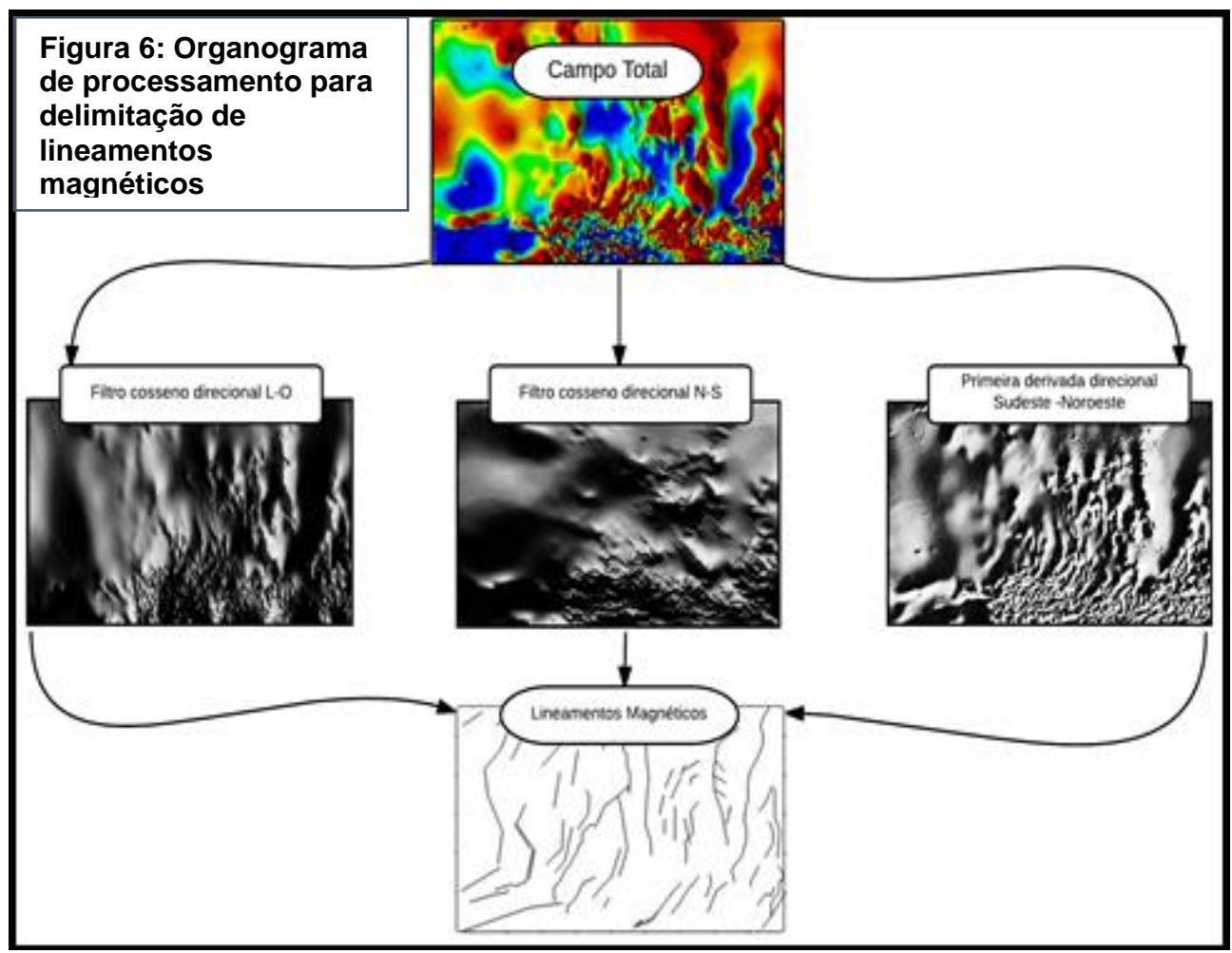

informações das profundidades dos corpos magnetizados anômalos. Como já citado primeiramente as derivadas direcionais são efetuadas e posteriormente deconvolvidas.

Observa-se as profundidades dos corpos anômalos de 100 até aproximadamente 3000 metros. Analisando esta figura, nota-se a presença de corpos mais rasos ao sul e extremo sudeste da imagem, que é coincidente com os pequenos corpos e feições geológicas já mapeadas nesta área. As demais áreas nesta imagem como as anomalias, que serão discutidas na próxima etapa de processamento, sendo que estes corpos citados se encontram em profundidades maiores que 1500 metros

Depois das análises qualitativas citadas anteriormente foram feitas nesta etapa do trabalho análises semiqualitativas, ocasião em que lineamentos magnéticos foram traçados seguindo o fluxograma acima (figura 6). Observando as transformações do campo do capítulo anterior, nota-se que as feições magnéticas seguem uma direção padrão de sudoeste para noroeste uma derivação direcional foi feita na direção oposta a este "trend" de feições para ressaltar os lineamentos magnéticos principais da área.

O fluxograma abaixo (figura 7) mostra como fora efetuada a Deconvolução de Euler para obter

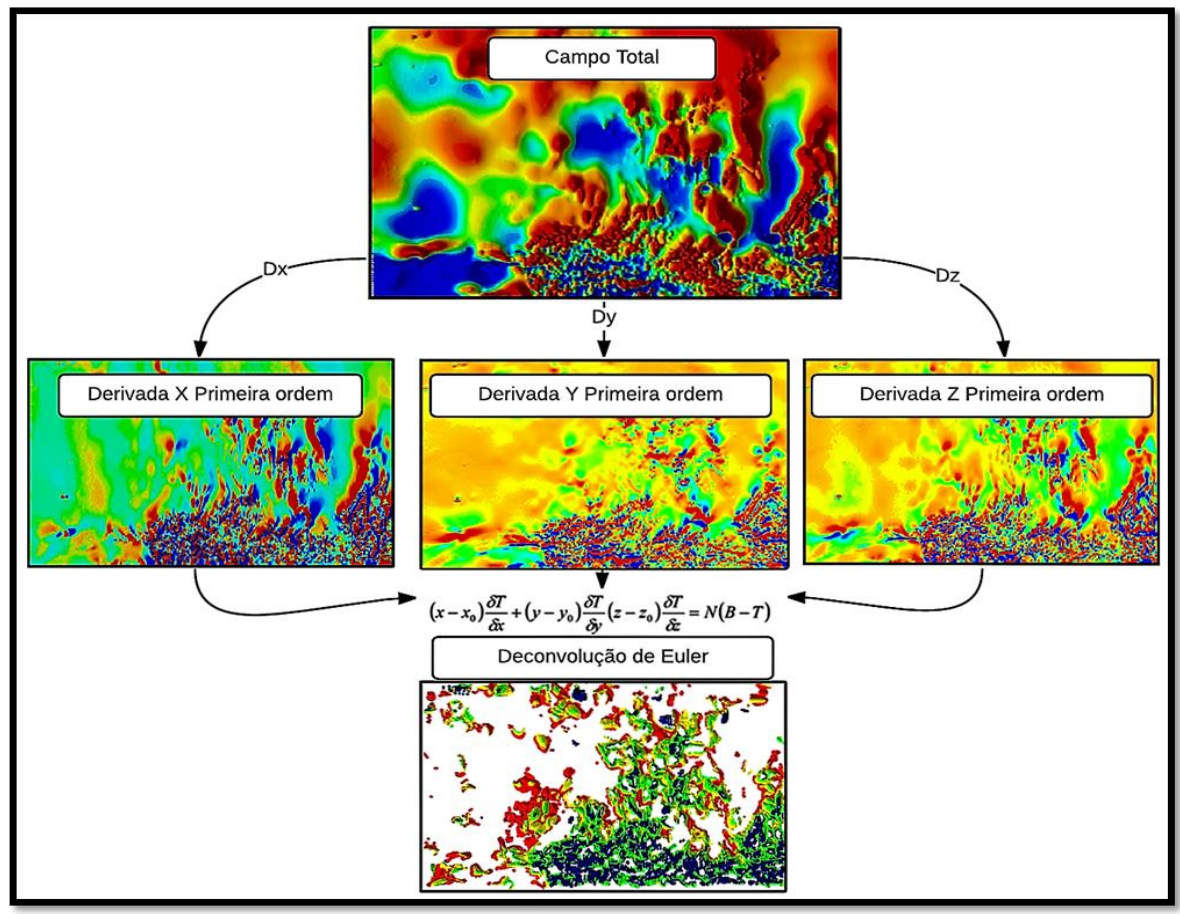

Figura 7: Metodologia para efetuação da Deconvolução de Euler para encontrar profundidade de corpos magnéticos anômalos 


\section{Interpretação}

Posteriormente todas imagens geradas foram analisadas individualmente e integradas mutualmente conforme 0 diagrama abaixo na figura 8 . Com o intuito de destacar regiões com alto potencial de ocorrência mineral (regiões anômalas)

$\mathrm{Na}$ figura 9 e 10 pode se observar a integração dos mapas interpretativos entre os mapas dos lineamentos magnéticos o mapa das áreas anômalas interpretada, além de o quadrado ao interior da imagem é referente a figura 9 que é um mapa interpretativo desta área disponibilizado pela companhia Havilah Resources com furos de sondagem efetuados pela mesma aonde foram encontrados cobre, ouro e zinco. Comparando-se as figuras verifica-se áreas de provável Hidrotermalismo, lineamentos magnéticos anomalias de corpos densos e ou com alto valor magnético.

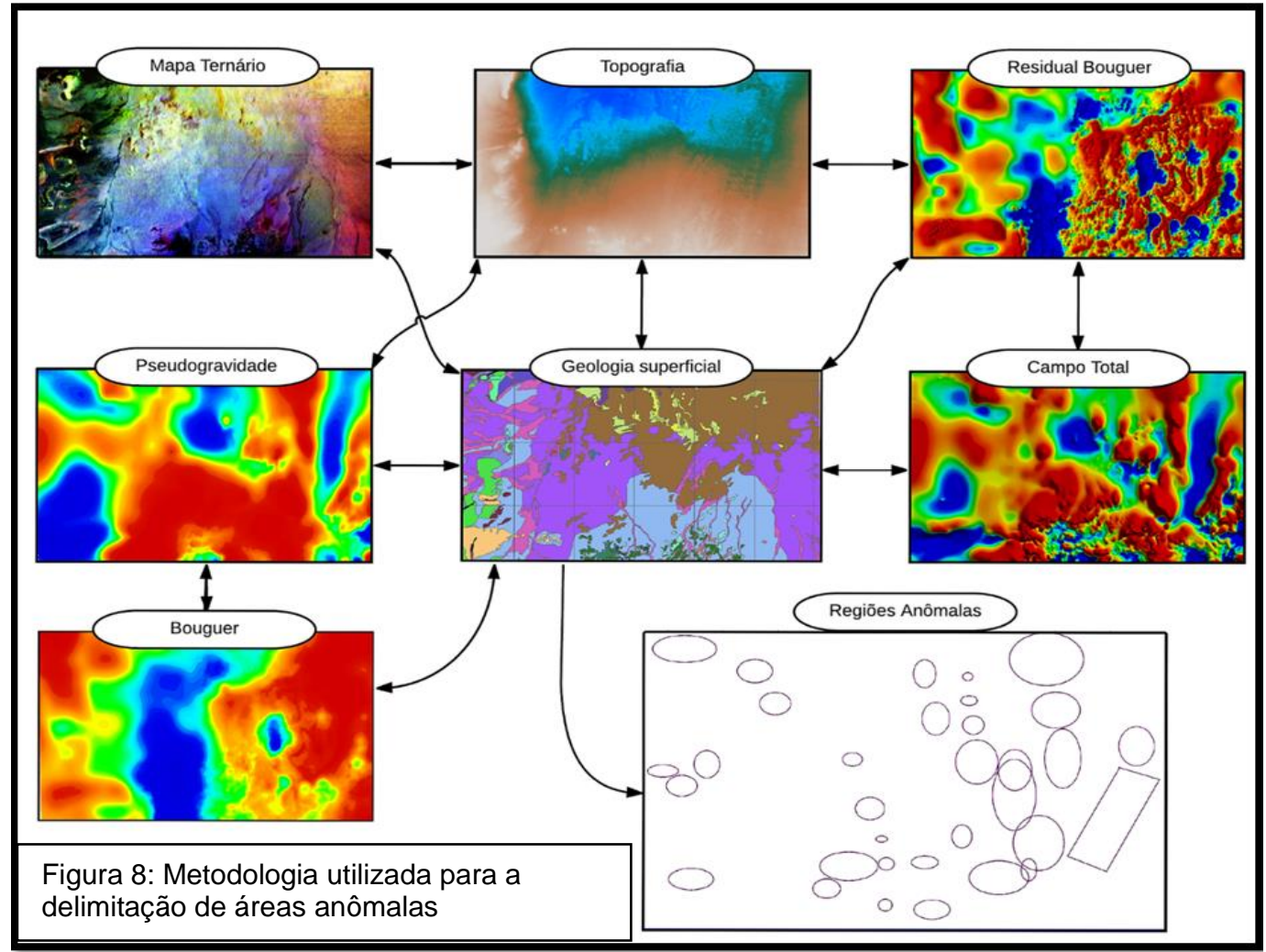

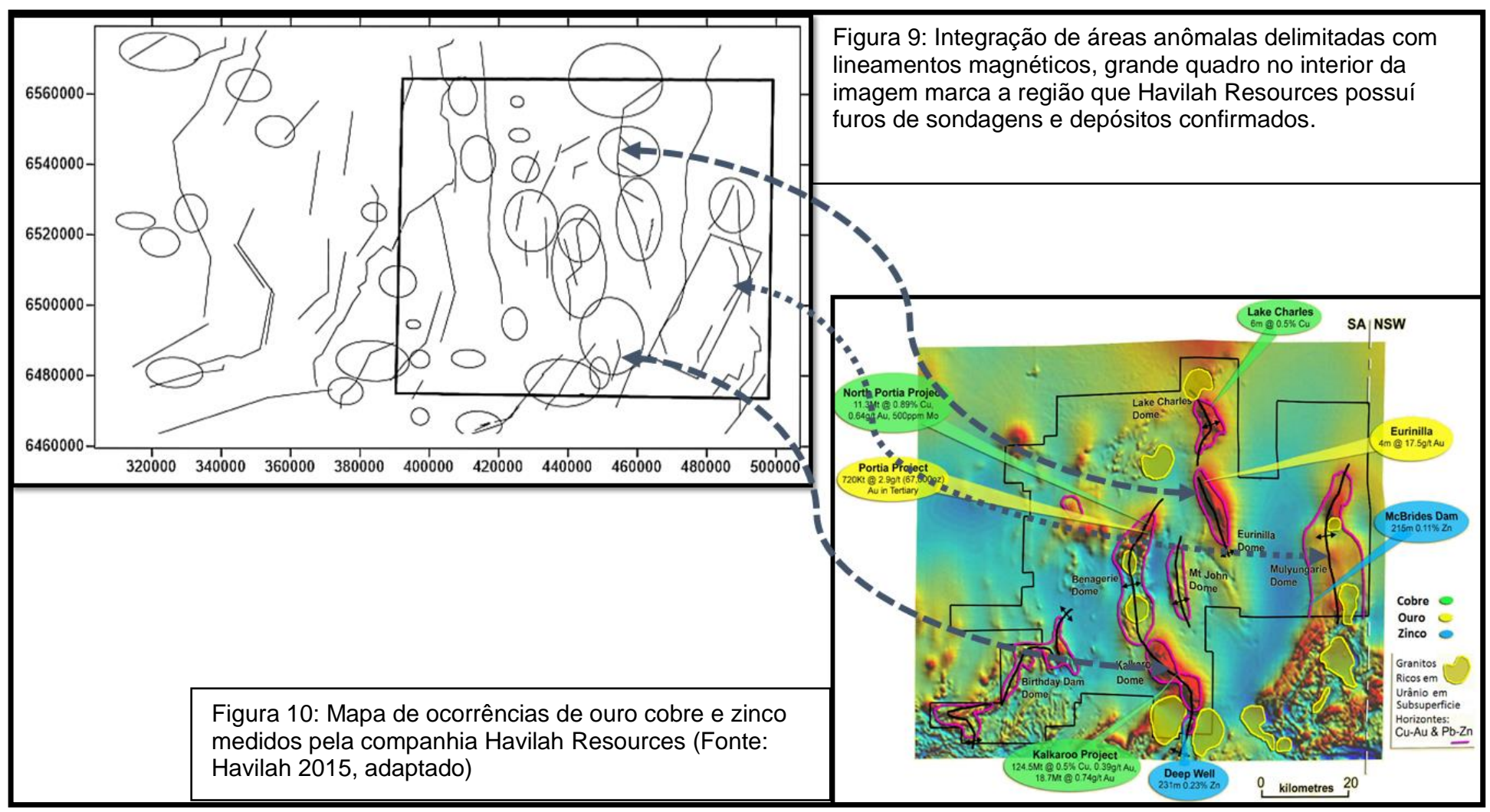




\section{Discussões e Conclusões}

As localidades delimitadas neste trabalho onde possuem altos valores de magnetização e alta densidade, juntamente com elevados valores de contagem de radioisótopos, são quase sempre coincidentes com as áreas onde a companhia responsável pela área aferiu ocorrências de metais ligados com hidrotermalismo em furos de sondagem.

Conclui-se o sucesso das técnicas efetuadas neste trabalho, porém, se é necessário efetuar estudos mais detalhados destas áreas. Recomenda-se levantamentos magnéticos e gamaespectrometricos de maior detalhe nas áreas delimitadas, enfatizando áreas onde possuem maiores valores de gama. No entanto, conforme a Deconvolução de Euler mostra, a grande maioria destas áreas anômalas aferidas são se dão em razão de corpos magnetizados em profundidade.

A utilização de métodos gravimétricos para este tipo de análise qualitativa de dados em escala regional não se mostrou muito eficiente, apenas contribuindo com poucas informações que reforçaram aquelas providenciados pelos mapas magnéticos. No entanto, cabe ressaltar que para o intuito de modelagem e estudo mais detalhado de corpos em subsuperfície,; porém, esta análise foge do foco deste trabalho, que é delimitar áreas para posterior análise.

\section{Acknowledgment}

A special thanks and gratitude to Christopher William Giles CEO of Havilah resources and friend who made this work possible.

\section{Bibliografia e Referencias}

ASTER Global DEM Validation Summary Report from http://www.gdem.aster.ersdac.or.jp/index.jsp

Baranov, V., 1957, A new method for interpretation of aeromagnetic maps: Pseudogravimetric anomalies: Geophysics, 22, 359-382,

BARBOSA, Valéria C. F and SILVA, João B. C. Deconvolução de Euler: passado, presente e futuro - um tutorial. Rev. Bras. Geof. [online]. 2005, vol.23, n.3 [cited 2015-11-25], pp. 243-250

BLAKELY, Richard J.. Potential Theory in Gravity and Magnetic Applications. Cambridge University Press, 1996

DMC, International Imaging Australia mosaic (DMCii) 2013 [online] disponível em: http://www.arcgis.com/home/item.html?id=84ff40bb77e04 150817491bdb827ee5c [acessado em 25 jun. 2015].

Ferreira, F. J. F. Aerogamaespectrometria e aeromagnetometria de um trato ocidental do PréCambriano paulista. São Paulo, 1991. Tese de doutoramento Instituto de Geociências, Universidade de São Paulo. 170p.

MagPick V 3.05 - Magnetic processing and interpretation. 1996 - 1998 Hamburg University, Germany. 2010 Geometrics, Inc. USA
MINTY, B. R. S. The fundamentals of airborne gammaray spectrometry. AGSO Journal of Australian Geology and Geophysics , v. 17, n. 2, p. 39-50, 1997.

MINTY, B. R. S.; LUYENDY, A. P. J ; BRODIE, R. C. Calibration and data processing for airborne gamma-ray spectrometry. AGSO Journal of Australian Geology \& Geophysics, v. 17, n. 2, p. 51-62, 1997

Nabighian, M. N., 1984. Toward a three-dimensional automatic interpretation of potential field data via generalized Hilbert transforms: Fundamental relations: Geophysics,, 49, 780-786.

Nabighian, M.N. 1972. The analytical signal of twodimensional magnetic bodies with poligonal cross-section :its properties and use for automated anomaly interpretation. Geophysics, v. 37, p. 507-517.

Naidu, P. S.; Mathew M. P., 1998. Analysis of Geophysical Potential Fields - A digital signal Processing Approach. Amsterdam. Elsevier, p. 176-177.

Pacca, I.G., Ernesto M. Investigações paleomagnéticas no Brazil congresso de geofísica da américa latina 1979

Panepinto*, Stefano et al. 'Using The Pseudo-Gravity Functional Transform To Enhance Deep-Magnetic Sources And Enrich Regional Gravity Data'. SEG Technical Program Expanded Abstracts 2014 (2014)

Ramos L. N R. Dados gamaespectrometricos e magnetometricos aéreos aplicados ao mapeamento geológico e à exploração de ouro na região de Fazenda Nova, porção leste do arco magmático de Arenópolis Goiás, 2010. Tese de mestrado Instituto de Geociências, Universidade de Brasília.

Raymond, O.L., Retter, A.J., (editors), 2010. Surface geology of Australia 1:1,000,000 scale, 2010 edition [Digital Dataset] Geoscience Australia, Commonwealth of Australia, Canberra.

Roest W.R., Verhoef J., Pilkington M. 1992. Magnetic interpretation using the 3-D analytic signal. Geophysics 57, 116125.

Sarig, South Australian Resource Information Geoserver (2015). Webtop Log In. [online] Disponivel em: https://sarigbasis.pir.sa.gov.au/WebtopEw/ws/catapp/sari $\mathrm{g} / \mathrm{cat}$

/Record?w=version_highest_version_key=\%272962\%27 [acessado em 30 jun. 2015].

Surfer, Version 9.11.947 - Surface Mapping System, Copyright 1993 - 2010Golden Software, Inc.

Wade, Claire. 2014. 'Granitic and Volcanic Rocks of the Curnamona Province and Their Relationship to Mineralization'. Adelaide: AIG South Australia Branch Technical Talk1-15. Web. 25 June 2015. Turner, F. J. \& Werhoogen, J., 1960. Igneous and metamorphic petrology. 2nd ed., McGraw Hill, New York, USA. 